Article

\title{
The Citizens' Views on Adaptation to Bioclimatic Housing Design: Case Study from Greece
}

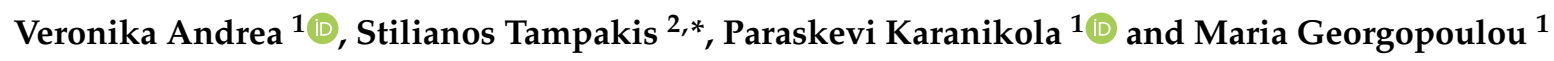 \\ 1 Department of Forestry and Management of the Environment and Natural Resources, \\ Democritus University of Thrace, 68200 Orestiada, Greece; vandrea@fmenr.duth.gr (V.A.); \\ pkaranik@fmenr.duth.gr (P.K.); mar.georgopoulou@gmail.com (M.G.) \\ 2 School of Forestry and Natural Environment, Faculty of Agriculture, Forestry and Natural Environment, \\ Aristotle University of Thessaloniki, 54124 Thessaloniki, Greece \\ * Correspondence: stampaki@for.auth.gr; Tel.: +30-231-099-2756
}

Received: 2 May 2020; Accepted: 12 June 2020; Published: 18 June 2020

check for updates

\begin{abstract}
Bioclimatic housing design is regarded as an important pillar towards energy policies. Additionally, it is closely affiliated with the performance of energy efficiency of buildings. The citizens' views and their adaptation to energy saving practices can be utilized as an important data base in order to design, improve and properly manage urbanization and environmental challenges in the residential sector. For the capitalization of the citizens' views in Orestiada, the newest city in Greece, simple random sampling was applied on data that were collected via personal interviews and with the use of a structured questionnaire. Reliability and factor analyses were applied for the data processing along with hierarchical log-linear analysis. The latter was utilized for the statistical clustering of citizens into given distinct groups-clusters, arising by factor analysis. The main findings revealed that the citizens are merely aware of bioclimatic principles, while only a small percentage of $28.8 \%$ adopts some primary bioclimatic disciplines. Conclusively, it should be noted that there is a need for effective planning towards empowerment on energy efficiency in the residential sector of the city. Notwithstanding, it should not be disregarded the need for the incorporation of conceptual frameworks in urban planning. This is an approach that prerequisites public awareness and the stakeholders' participation in decision making processes.
\end{abstract}

Keywords: bioclimatic buildings; sustainable buildings; bioclimatic housing design; energy efficiency; citizens' views; raising-awareness; adaptation; decision making

\section{Introduction}

The current allocation of urbanization indicates that some $55 \%$ of the population worldwide live in cities. It is true that if this trend continues by 2050 , the urban population will exceed the double of its current size [1]. Intense urbanization could be explained as an indicator of economic and social advance. However, it constitutes an important means that puts pressure on the infrastructure and resilience of our planet [2]. At the same time, cities have to deal with great technological advances, which inevitably cause constant environmental degradation and exhaustion of the natural resources. In particular, most of the countries worldwide are called to handle high urbanization, which in turn leads to an increase of their ecological footprint. There is also a record indicating the deterioration of the ecosystem's capacity. Cities are the main pillars of both economic motion and energy consumption [3]. Certainly, urban areas constitute complex ecosystems with special features. In fact, they operate as integrated units and extensive entities of multilevel and critical interactions that demand significant amounts of energy for their operational needs [4]. Intrinsically, this is how they should be considered, as integrated systems. 
However, a crucial sustainability challenge still remains on how to enhance environmental quality and simultaneously accomplish the humans' development goals. Therefore, a challenging target in urban planning stands in the development of cities that will provide the prerequisites for better standards in the quality of life. Some of the most important ones are quality, health and safety and sustainability in all aspects of societal cohesion. Though, in setting a conceptual basis for effective urban planning, it presupposes the balance of natural ecosystems and the viability of cities [5].

The geographical allocation of the urban population is considered as an important characteristic for the better understanding of the citizens' environmental awareness and consciousness [6]. Moreover, the identification and efficient management of vital developments in the performance of ecosystem services should be used for sustainability purposes and in order to ensure a better quality of life for citizens. To this end, the citizens' adaptation to energy efficiency measures is considered as a priority. Special attention has been shown over the last decade, by the European policies on operational energy use. In fact, all the European Commission (EC) strategies and new measures are moving towards the design of new smart buildings. These buildings are supposed to have extremely low energy demands. Additionally, the EC policies include embodied energy of buildings and the development of sustainable buildings. More specifically, EC policy decisions aim to sustainable use of resources throughout their life cycle in achieving significant reduction on their environmental impacts [7]. In addition, the concept of smart cities is listed as a substantial goal for EC. Under this scheme, European cities are expected to transform into units that will provide a better quality of life for their citizens, taking into consideration both technical and political processes. Thus, the exploitation of smart citizens' typology is critical in order to design the required infrastructures. The latter should be determined through a procedure that has the citizens' participation in decision making as a major prerequisite [8].

Moreover, it should be noted that houses represent the major part of the existing buildings in most urban areas. For this particular purpose, bioclimatic housing design should be regarded as a field of special attention. Bioclimatic architecture principles are used to improve the housing energy efficiency through the proper capitalization of the existing environmental and location conditions, such as temperature, humidity, solar radiation and prevailing winds [9]. An expected solution among several habitability optimum conditions, is the thermal comfort achieved by least energy consumption, so that a residence satisfies the citizens' needs for health and wellness. Thus, the citizens' views, as building users, are important sources of information towards effective indoor environmental quality performance and adaptation level on bioclimatic measures [10]. Moreover, recent research has indicated that bioclimatic design should not be focused exclusively on indoor environments. In fact, outdoor assets such as balconies and the outdoor surroundings should be regarded as an integrated unit in efficient bioclimatic design, while it is of utmost importance for future research to shed light into the associations among certain community practices, features and their adaptation to bioclimatic housing design [11].

\section{The Energy Efficiency Performance Status for Buildings in the Study Area}

The building sector is very significant for energy and environmental goals of EC. Not to mention, that smart and sustainable buildings are proven to effectively contribute to the social and financial level of cities, formatting the standards for a better quality of life [12]. Energy efficiency is considered as a major matter for the building sector in Europe. Therefore, EC has issued two directives for all its members to comply with in the energy sector. Namely, Directive 2010/31/EU (EPBD), attributed to Energy Performance of Buildings, and Directive 2012/27/EU, addressing the Energy Efficiency scheme. In Greece, EPBD transposition was enacted by the national law N.3661/2008. The "Hellenic Regulation on the Energy Efficiency of Buildings-KENAK" outlines the general calculation approach in line with the European principles. Indeed, the Technical Chamber of Greece has prepared and elaboratively explained all the technical requirements included in KENAK.

In 2010, a Presidential Decree (PD 100/2010) was issued including: the qualifications required from the construction field professionals; new capacity building and vocational training framework; 
monitoring systems; the specific regulations needed by experts in order to perform the energy audits of buildings; and inspections of heating and air-conditioning systems. Consequently, from January 2011, the energy performance assessment was mandatory for new buildings including energy performance certificates [13].

According to the 2011 Census of Buildings by the Hellenic Statistical Authority, $55 \%$ of the country's residential buildings were built before 1980, which means that they are thermally unprotected. Due to the economic crisis, the number of buildings built after 2010 with KENAK's minimum requirements were estimated as being only $1.5 \%$ in the building stock of Greece. In the Region of Eastern Macedonia and Thrace, that the Municipality of Orestiada administratively belongs, the vast majority of buildings are residential ones. Taking for granted that KENAK came into force in 2010, it is clear that the building stock of the Municipality of Orestiada does not meet the energy efficiency standards according to the European directives.

The age of the buildings can be divided into three main periods. These are grouped according to the existing legal framework. The legislation was initially adopted in 1980 with the introduction of Hellenic Building Thermal Insulation Regulation and updated in 2010 with the implementation of KENAK. Consequently, the age classes that affect energy efficiency in the buildings of Orestiada are the following four:

(1) First class: Buildings constructed before 1980. There is no thermal insulation regulation and these buildings are thermally unprotected.

(2) Second class: Buildings constructed from 1981 to 2000, when the Building Thermal Insulation Regulation was put in force.

(3) Third class: Buildings constructed from 2001 to 2010. These buildings meet more construction standards, namely the standards of Hellenic Building Thermal Insulation Regulation; Greek seismic code; and the Greek Regulation for Reinforced Concrete that was put in force in 2000.

(4) Fourth class: Buildings constructed from 2010 until today, in which KENAK is applied.

The aim of the study was to investigate the citizens' views on the basic principles of bioclimatic housing design and further analyzes their adaptation level to certain patterns and measures implemented in their houses. The study is expected to serve as indicative for areas with similar characteristics as Orestiada, while a point to underline is that the oldest buildings are less than 100 years old in the total area of the Municipality. The specific objectives focus on the citizens' facilitation in adapting energy efficiency attitudes in the residential sector, serving the need for a transition to a low-carbon society. The main findings underscore low adaptation on bioclimatic housing design principles mainly restricted on passive solar systems. Furthermore, light was shed on the institutional framework that should be developed, including the development of decision making processes towards multilevel cooperation of key stakeholders in the energy performance of buildings. It is therefore apprised the imperative for environmental raising awareness strategies devoted to the citizens.

\section{Materials and Methods}

\subsection{Study Area}

The Municipality of Orestiada (Figure 1) as an administrative unit belongs to the Prefecture of Eastern Macedonia and Thrace, situated in the Regional Union of Evros in Greece. This municipality was established in 2011. Before 2011 the former Municipalities were four including Orestiada, Vissa, Trigono, and Kiprinos. Orestiada is situated in the northernmost part of Greece, bordering with Bulgaria to the north and Turkey to the east. The total holding of the Municipality is $955.6 \mathrm{~km}^{2}$ and the population is estimated as being 37,695 inhabitants according to the 2011 census. The seat of the municipality is the city of Orestiada, with a population of 18,426 citizens according to the 2011 census. Orestiada has an altitude of $40 \mathrm{~m}$ above sea level. It is the most newly established city in Greece that was constructed after the Lausanne Treaty in 1923. The first citizens were refugees from Karagats and 
Andrianoupolis. In terms of urbanity, it is mainly an urban municipality with an important primary development sector. Regarding its architecture, it is characterized by its modern street plan, while the topographic plan of the city aged in 1923, is characterized by the exemplary road construction, wide one-way streets and large squares (Figure 2) that most of the modern Greek cities lack.
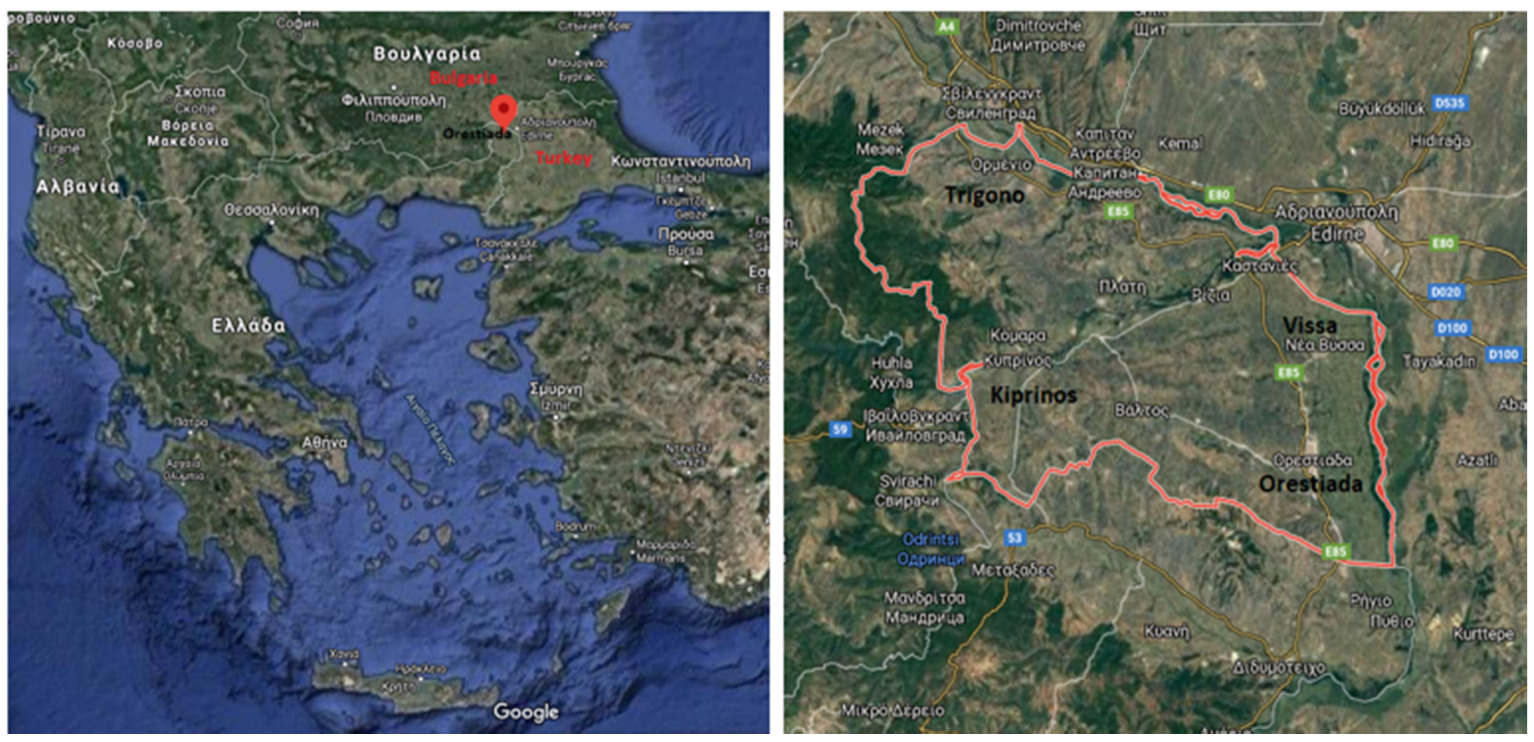

Figure 1. The location and map of the Municipality of Orestiada, Greece (source: Google Maps).

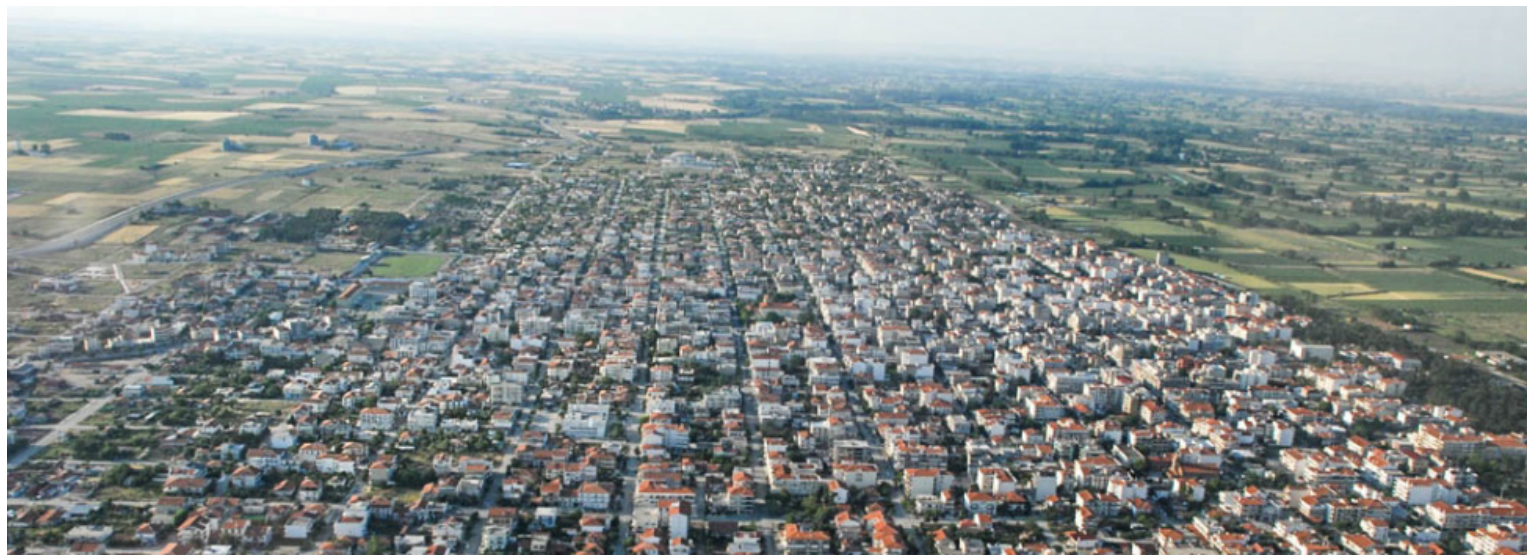

Figure 2. The city of Orestiada, Greece (source: Municipality of Orestiada).

\subsection{The Survey}

The population that took part in the study included the households in the Municipality of Orestiada. As sampling procedure framework, the domestic electricity consumers' list was chosen. The utilization of households for the sampling procedure constitutes a common example of using teams rather than sample units. In fact, it is considered as an efficient method which is also less pricey [14]. Moreover, interviews took place with a face-to-face method and simple random sampling was applied $[15,16]$. The average time for the interview was estimated as lasting approximately $25 \mathrm{~min}$. The survey was divided into four sections:

(1) The demographic profile of the locals;

(2) Bioclimatic housing design and the house surroundings;

(3) Adaptation to environmentally friendly and energy efficiency practices;

(4) The implementation of Hierarchical log-linear analysis on the citizens' awareness on bioclimatic housing design. 
The data collection was conducted in 2018 from March to May. The interviews were assigned to a skilled student on the interviewing method, and were conducted during 17:00-21:00 on both weekdays and weekends. The households were selected in a random way by the use of random number tables. The personal interviews took place with the contribution of one family member per household. The rate of response was estimated as being very high $(98 \%)$ for the survey. The participants ought to have been 18 years old or older in order to comply with the restrictions in Greek law. In case a member of a household could not be found or denied to fulfil the questionnaire, new sample units were chosen.

In order to collect the data, there were organized face-to-face interviews by the use of a structured questionnaire. The questions involved various topics and they were formatted by Likert-scaled and/or close-ended questions. The questionnaire aimed to investigate the citizens' views on bioclimatic housing design principles, energy efficiency practices they implement, the establishment and utilization of green spaces in the buildings, the means of heating and cooling installations they use, the utilization of renewable energy, and their attitudes addressing participation in environmental decision making and awareness. The questionnaire used in the survey is provided in the Supplementary Materials.

\subsection{Research Method}

The research method used simple random sampling and according to its formulas, there were estimated the numerical mean $(y)$, the standard error $(s)$ for the quantitative variables, and for the standard error for population proportion $(S p)$ addressing the qualitative variables [14]. The survey was conducted through personal interviews and with the use of a structured questionnaire. The population that took part in the study was the total of the citizens in the households of Orestiada, Greece.

To estimate the sample size, pre-sampling was implemented. The sample size was determined as being 50 citizens. Thus, for each quantitative variable, its variation or standard deviation was determined, and for each qualitative variable, the proportion was calculated [14]. The finite population correction should be disregarded due to the fact that $n$ the size of the sample is high compared with the population $\mathrm{N} 30$ size [16]. The utilization of a questionnaire is not restricted in the estimation of a single variable of the population, yet is addressed to more variables. Thus, the calculation provided a sample size of 400 citizens (for probability $(1-\alpha) 100=95 \%, e=0.049$ and without the correction of the finite population). The collection of the research data was conducted in 2018 with the use of SPSS statistical package for the data processing.

Two analyses-reliability and factor were used for the multivariable processing [17]. In order, to examine the questionnaire's internal reliability [18], namely if the data had the tendency to evaluate the same thing, the Cronbach's reliability coefficient was used. A coefficient is regarded satisfactory when its value is equal or higher than 0.70 [19]. Moreover, coefficients with values higher than 0.80 are regarded very satisfactory. Practically, values lower than 0.60 for reliability coefficients are acceptable in various studies [14].

In order for the tests to be useful, reliability must be ensured. In particular, reliability must also be valid, which is controlled via the implementation of factor analysis [16]. The latter constitutes a statistical method that is used in order to examine the existent common factors inside a group of variables [17]. Especially, another analysis was implemented, termed principal component analysis. This analysis is using a spectral analysis of the variance (correlation) matrix. The option of the specific number of factors is a process characterized by special dynamics. It also requires the assessment of the model in a repeated performance. The solution of two factors was applied in the case study. Furthermore, the rotation of the matrix principal components was implemented with the aim of the maximum variance rotation method, suggested by Kaiser [20,21]. It should be taken into consideration that when it should be determined which of the variables belong to a specific factor, the loads in this factor play a critical role. This means that after their rotation, the variables belong to that factor where their loads appear higher than 0.5 [18].

Hierarchical log-linear analysis was utilized for the statistical clustering of citizens into given distinct groups-clusters arising by the factor analysis. This analysis was used to examine two groups 
of variables. Namely, the adaptation to environmentally friendly practices for energy efficiency (continuous variables) and the citizens' views on the bioclimatic housing design (categorical variables). This analysis serves as an exploratory tool that aims to identify clusters of similar objects in a large number of observations. The condition is then accepted that the variables are independent, which allows the manipulation of categorical and continuous variables simultaneously, with the former following a polynomial distribution and the latter a normal distribution. Before the implementation of hierarchical log-linear analysis, the anticipated frequencies in the contingency table were examined. The classes were practically grouped in order to meet the criteria described by Tabachick and Fidell [22].

In addition, with the implementation of Pearson's $X^{2}$ check, the relationship between other variables and each cluster was investigated separately. Therefore, for each cluster, it was possible to recognize its identity in a more accurate way.

\section{Results}

\subsection{The Demographic Profile of the Citizens}

The investigated population included the citizens of the Municipality of Orestiada, Greece. The establishment of the municipality is the most recent one in Greece, and accordingly, the housing took place from 1923 and beyond. It is characterized by modern street and topographic plans, while the oldest house is built after 1923. The locals' demographic features were collected during the interviews. From the representations of Table 1 , it is apparent that the majority are men (57.2\%), aged between $18-30$ years old $(39.0 \%)$; married $(74.5 \%)$ with two children (41.0\%), having completed high school education (29.5\%). Regarding their occupation, they were mostly public servants (28\%).

Table 1. Demographic characteristics of the locals.

\begin{tabular}{ccccc}
\hline Gender & Male & Female & & \\
\hline Age & $57.2 \%\left(\mathrm{~s}_{\mathrm{p}}=0.0247\right)$ & $42.8 \%\left(\mathrm{~s}_{\mathrm{p}}=0.0247\right)$ & $\mathbf{4 1 - 5 0}$ & $>\mathbf{5 0}$ \\
& $\mathbf{1 8 - 3 0}$ & $\mathbf{3 1 - 4 0}$ & $36.2 \%\left(\mathrm{~s}_{\mathrm{p}}=0.0240\right)$ & $30.5 \%\left(\mathrm{~s}_{\mathrm{p}}=0.0230\right)$ \\
Marital Status & $\begin{array}{c}39.0 \%\left(\mathrm{~s}_{\mathrm{p}}=0.0244\right) \\
\text { Unmarried }\end{array}$ & $\begin{array}{c}23.5 \%\left(\mathrm{~s}_{\mathrm{p}}=0.0212\right) \\
\text { Married }\end{array}$ & $\begin{array}{c}\text { Divorced or Widowed } \\
6.2 \%\left(\mathrm{~s}_{\mathrm{p}}=0.0121\right)\end{array}$ & \\
Childhood & $19.2 \%\left(\mathrm{~s}_{\mathrm{p}}=0.0197\right)$ & $74.5 \%\left(\mathrm{~s}_{\mathrm{p}}=0.0218\right)$ & & \\
without Children & One Child & Two Children & Three Children & More than Three \\
$22.2 \%\left(\mathrm{~s}_{\mathrm{p}}=0.0208\right)$ & $22.0 \%\left(\mathrm{~s}_{\mathrm{p}}=0.0207\right)$ & $41.0 \%\left(\mathrm{~s}_{\mathrm{p}}=0.0246\right)$ & $14.5 \%\left(\mathrm{~s}_{\mathrm{p}}=0.0176\right)$ & $0.2 \%\left(\mathrm{~s}_{\mathrm{p}}=0.0025\right)$ \\
Educational Level & Primary School & Secondary School & Technical School & \\
& $4.2 \%\left(\mathrm{~s}_{\mathrm{p}}=0.0101\right)$ & $8.2 \%\left(\mathrm{~s}_{\mathrm{p}}=0.0138\right)$ & $15.0 \%\left(\mathrm{~s}_{\mathrm{p}}=0.0179\right)$ & \\
& High School & Technological Ed. & University & \\
Profession & $29.5 \%\left(\mathrm{~s}_{\mathrm{p}}=0.0228\right)$ & $16.8 \%\left(\mathrm{~s}_{\mathrm{p}}=0.0187\right)$ & $25.2 \%\left(\mathrm{~s}_{\mathrm{p}}=0.0217\right)$ & \\
Laborer & Private Employee & Public Servants & Fivestock farmers & Pensioners \\
$0.8 \%\left(\mathrm{~s}_{\mathrm{p}}=0.0043\right)$ & $18.2 \%\left(\mathrm{~s}_{\mathrm{p}}=0.0193\right)$ & $28.0 \%\left(\mathrm{~s}_{\mathrm{p}}=0.0224\right)$ & $7.2 \%\left(\mathrm{~s}_{\mathrm{p}}=0.0130\right)$ & $14.5 \%\left(\mathrm{~s}_{\mathrm{p}}=0.0176\right)$ \\
Freelancers & Students & Housewives & Unemployed & \\
$21.2 \%\left(\mathrm{~s}_{\mathrm{p}}=0.0205\right)$ & $1.8 \%\left(\mathrm{~s}_{\mathrm{p}}=0.0066\right)$ & $5.0 \%\left(\mathrm{~s}_{\mathrm{p}}=0.0109\right)$ & $3.2 \%\left(\mathrm{~s}_{\mathrm{p}}=0.0089\right)$ & \\
\hline
\end{tabular}

\subsection{Bioclimatic Housing Design and the House Surroundings}

The majority of the citizens agreed that there is need to embrace bioclimatic housing design by the design phase of the buildings that will passively meet their needs for heating and cooling. In particular, more than half of the residents $(55.8 \%$, sp $=0.0248)$ totally agree to its implementation in houses, while an important percentage of $35.5 \%(\mathrm{sp}=0.0239)$ also agrees. $7.5 \%(\mathrm{sp}=0.0132)$ of the citizens have no opinion as they stated neither agree nor disagree. Finally, a small percentage of $1.2 \%(\mathrm{sp}=0.0056)$ disagree and consider that bioclimatic design is not necessary in homes.

However, their knowledge on passive solar systems appears to be limited as merely the $29.80 \%$ are aware that the south side of the building is important for the efficient exploitation of solar radiation (Table 2$)$. On the contrary, more than half $(55.0 \%)$ seem to recognize the importance of the northern side 
for proper wind protection and heat retention; yet, even in this case, the results indicate that citizens' awareness on bioclimatic housing design remains at low levels.

Table 2. Building side-exploitation of solar radiation and protection from winds and removal of the heat.

\begin{tabular}{ccc}
\hline Building Side & Exploitation of Solar Radiation & $\begin{array}{c}\text { Protection from Winds/Removal } \\
\text { of the Heat }\end{array}$ \\
\hline to the north & $17.2 \%, \mathrm{~s}_{\mathrm{p}}=0.0189$ & $55.0 \%, \mathrm{~s}_{\mathrm{p}}=0.0249$ \\
to the east & $27.5 \%, \mathrm{~s}_{\mathrm{p}}=0.0223$ & $10.0 \%, \mathrm{~s}_{\mathrm{p}}=0.0150$ \\
to the south & $29.8 \%, \mathrm{~s}_{\mathrm{p}}=0.0229$ & $15.2 \%, \mathrm{~s}_{\mathrm{p}}=0.0180$ \\
to the west & $17.0 \%, \mathrm{~s}_{\mathrm{p}}=0.0188$ & $8.2 \%, \mathrm{~s}_{\mathrm{p}}=0.0138$ \\
not aware & $8.5 \%, \mathrm{~s}_{\mathrm{p}}=0.0139$ & $11.5 \%, \mathrm{~s}_{\mathrm{p}}=0.0153$ \\
\hline
\end{tabular}

More specifically, $37.8 \%$ of respondents state that there are openings (doors and/or windows) of average size to the north side of the building, while only $34.0 \%$ state that there are openings of average size with a south orientation (Table 3) in their residence. The openings to the south serve as a solar collector, so there should be double glazed, insulated window coverings and proper placement of the door frames [23].

Table 3. The openings' size (doors and windows) on the north-south axis in the citizens' residences.

\begin{tabular}{ccccc}
\hline Openings' Size & Wide & Average & Narrow & Do Not Exist \\
\hline to the north & $8.8 \%, \mathrm{~s}_{\mathrm{p}}=0.0141$ & $37.8 \%, \mathrm{~s}_{\mathrm{p}}=0.0242$ & $25.0 \%, \mathrm{~s}_{\mathrm{p}}=0.0217$ & $28.5 \%, \mathrm{~s}_{\mathrm{p}}=0.0226$ \\
to the east & $39.5 \%, \mathrm{~s}_{\mathrm{p}}=0.0244$ & $38.0 \%, \mathrm{~s}_{\mathrm{p}}=0.0243$ & $6.2 \%, \mathrm{~s}_{\mathrm{p}}=0.0121$ & $16.2 \%, \mathrm{~s}_{\mathrm{p}}=0.0184$ \\
to the south & $32.2 \%, \mathrm{~s}_{\mathrm{p}}=0.0234$ & $34.0 \%, \mathrm{~s}_{\mathrm{p}}=0.0237$ & $6.5 \%, \mathrm{~s}_{\mathrm{p}}=0.0123$ & $27.2 \%, \mathrm{~s}_{\mathrm{p}}=0.0223$ \\
to the west & $21.0 \%, \mathrm{~s}_{\mathrm{p}}=0.0204$ & $48.5 \%, \mathrm{~s}_{\mathrm{p}}=0.0250$ & $7.5 \%, \mathrm{~s}_{\mathrm{p}}=0.0132$ & $23.0 \%, \mathrm{~s}_{\mathrm{p}}=0.021$ \\
\hline
\end{tabular}

Thus, for the northern latitudes (including the research area), large openings are suggested to be designed to the south including single or double glazing. Moreover, openings of average dimensions on the eastern and western walls are also ideal for this geographical area, while narrow openings with double glazing should be considered as efficient for the northern side of the buildings [24]. The findings reveal that in Orestiada, the suggested principles of bioclimatic housing design are not widely adapted. Namely, the openings oriented to the south are recorded as average size by $34 \%$ of the citizens and as wide by $32.2 \%$. As regards to the openings to the east, $39.5 \%$ claim to have wide openings and $38 \%$ have average ones. The north openings are of average size for $37.8 \%$ of the houses and there are narrow openings in $25 \%$ of the homes with no openings to the north for $28.5 \%$ homes (Table 3 ). The data reflects a neutral conceptualization by the citizens regarding passive solar systems applied as part of bioclimatic housing design that is focused on the placement of openings (windows, doors, etc.). Indeed, the design of openings took place during the design phase of the building. However, it could be regarded as positive that primary steps towards bioclimatic housing design are adopted by the construction field and professionals of Orestiada for the orientation of openings.

Concerning the interior space installations on the north-south axis, it is evident that for the dining room and living room, there is preference for installation in the middle of the house (35.8\% and $32.8 \%$ respectively). The kitchen and the toilet are located to the north (35.5\% and $34.8 \%$ respectively); and the bedrooms to the south (39.2\%) and to the north (35\%) (Table 4). During the design phase of interior spaces, these rooms should be organized and grouped in a more efficient way. Design should be based on the fact that spaces which will be used the most should be placed to the south side of the building in order to ensure the desired thermal comfort where high levels are usually preferred. In contrast, for tspaces that are not used as often, there are restricted demands for thermal comfort conditions such as high temperatures. These spaces should be placed in the intermediate thermal zone. The rest of the spaces, usually the auxiliary ones, should be placed on the north side of the building, in order to 
provide a kind of "protection zone" and insulate the other two space categories. By following these basic installation principles for interior spaces, it is possible to separate the external environment from the internal one, in which mainly higher temperatures prevail. This is a convenient way to reduce energy losses from the most used spaces of the house [25]. According to the findings, interior space installations on the north-south axis are randomly set in the houses of Orestiada. An explanation could be that the designers did not prioritize this principle. In other cases, we would expect, at least for the living room, to be situated mainly to the south. Construction experts might list, as more important, other features such as the better utilization of the plot and the premises of the building, or the view from the rooms.

Table 4. Interior space installations on the north-south axis.

\begin{tabular}{ccccc}
\hline $\begin{array}{c}\text { Interior Space } \\
\text { Installations }\end{array}$ & North & $\begin{array}{c}\text { In the Middle of } \\
\text { the House }\end{array}$ & South & Do Not Exist \\
\hline Bedrooms & $35.0 \%, \mathrm{~s}_{\mathrm{p}}=0.0238$ & $18.5 \%, \mathrm{~s}_{\mathrm{p}}=0.0194$ & $39.2 \%, \mathrm{~s}_{\mathrm{p}}=0.0244$ & $7.2 \%, \mathrm{~s}_{\mathrm{p}}=0.0130$ \\
Living room & $29.2 \%, \mathrm{~s}_{\mathrm{p}}=0.0227$ & $32.8 \%, \mathrm{~s}_{\mathrm{p}}=0.0235$ & $27.8 \%, \mathrm{~s}_{\mathrm{p}}=0.0224$ & $10.2 \%, \mathrm{~s}_{\mathrm{p}}=0.0152$ \\
Kitchen & $35.5 \%, \mathrm{~s}_{\mathrm{p}}=0.0239$ & $27.8 \%, \mathrm{~s}_{\mathrm{p}}=0.0224$ & $25.2 \%, \mathrm{~s}_{\mathrm{p}}=0.0217$ & $11.5 \%, \mathrm{~s}_{\mathrm{p}}=0.0160$ \\
Dining room & $22.0 \%, \mathrm{~s}_{\mathrm{p}}=0.0207$ & $35.8 \%, \mathrm{~s}_{\mathrm{p}}=0.0240$ & $27.2 \%, \mathrm{~s}_{\mathrm{p}}=0.0223$ & $15.0 \%, \mathrm{~s}_{\mathrm{p}}=0.0179$ \\
Toilet & $34.8 \%, \mathrm{~s}_{\mathrm{p}}=0.0238$ & $25.2 \%, \mathrm{~s}_{\mathrm{p}}=0.0217$ & $19.0 \%, \mathrm{~s}_{\mathrm{p}}=0.0196$ & $21.0 \%, \mathrm{~s}_{\mathrm{p}}=0.0204$ \\
\hline
\end{tabular}

Only a low percentage (25\%) of buildings have a southern orientation. The urban planning and layout of the main road network along the east-west or north-south axis is what predetermines the orientation of the facades of the buildings. This causes certain constraints to the designers as it is not possible to take advantage of the available environmental and thermal benefits. Inevitably, they are led to design buildings with many problems, such as overheating of interiors (in buildings with east or west orientation), as well as insolation from solar radiation concerning buildings with north orientation. Added to that, it should be noted that although southern orientation may be possible for the construction of a building, shading conditions that are established by the surrounding buildings could provoke an unpleasant thermal situation for residents. Thus, interactions between the height of the buildings and the width of the streets should be also taken into account [26].

The citizens were asked about the type of their residence. Respectively, 32.2\% (sp $=0.0234)$ answered that they live in a detached house, $25.5 \%$ ( $\mathrm{sp}=0.0218)$ on the first floor, $26 \%(\mathrm{sp}=0.0219)$ on the second and $16.3 \%(\mathrm{sp}=0.0184)$ reside in an apartment on a higher floor. Another issue to investigate for the type of residence is the surroundings and the outdoor environment. Trees and high neighboring buildings could affect homes from a bioclimatic point of view. Thus, the citizens were also asked about the house orientation on the north-south axis of the land upon which the building is situated. $34.5 \%(\mathrm{sp}=0.0238)$ are said to have a house in the middle of the plot, $34 \%(\mathrm{sp}=0.0237)$ south of the plot and $30.2 \%(\mathrm{sp}=0.0230)$ north of the plot, while $1.2 \%(\mathrm{sp}=0.0056)$ of the residents did not respond.

Furthermore, a high percentage of $64.2 \%(\mathrm{sp}=0.0240)$ answered that there is a garden in their residence while $35.8 \%(\mathrm{sp}=0.0240)$ claimed not to have one. The citizens that stated they had a garden were then asked to provide more information. Namely, regarding the size of the garden, $3.5 \%$ $(\mathrm{sp}=0.0092)$ said that it is over $300 \mathrm{~m}^{2} ; 7 \%(\mathrm{sp}=0.0128)$ have a garden between 150 and $300 \mathrm{~m}^{2} ; 19.8 \%$ $(\mathrm{sp}=0.0199)$ between 50 and $150 \mathrm{~m}^{2} ; 24 \%(\mathrm{sp}=0.0214)$ have a garden sized from 20 and $50 \mathrm{~m}^{2}$ and $10 \%(\mathrm{sp}=0.0150)$ have one smaller than $20 \mathrm{~m}^{2}$. Additionally, $17 \%(\mathrm{sp}=0.0188)$ of the citizens stated that the garden is located around the plot, $16.8 \%(\mathrm{sp}=0.0187)$ to the north, $15.5 \%(\mathrm{sp}=0.0181)$ to the south and $14.8 \%(\mathrm{sp}=0.0177)$ in the middle of the plot.

The number of evergreen and deciduous trees found in home gardens is given in Table 5, while the type of trees depended on the planting location as shown in Table 6. Trees and shrubs, which are porous barriers, allow crossing a part of the wind, reduce turbulence and create a wider protection zone. They are superior in terms of fencing in and reducing wind speed, as they can reduce wind speed by $50 \%$ at a distance equal to five times their height [27]. However, it seems that the citizens are 
not able to conceive that evergreen trees should be planted in northern locations to serve insulation means for cold northern winds in winter. In fact, they associate garden trees with the shade they offer during seasons of high temperatures. Thus, $36.8 \%(\mathrm{sp}=0.0241)$ of the citizens state that the best season to relax in their garden is spring, $19.8 \%(\mathrm{sp}=0.0199)$ in summer, $7.2 \%(\mathrm{sp}=0.0130)$ in autumn and $0.5 \%(\mathrm{sp}=0.0035)$ in winter. It should also be noted that $35.8 \%$ do not have a garden.

Table 5. Number of trees in the residence garden.

\begin{tabular}{ccc}
\hline No. of Trees in the Garden & Evergreen Trees & Deciduous Trees \\
\hline No tree & $47.0 \%, \mathrm{~s}_{\mathrm{p}}=0.0250$ & $51.0 \%, \mathrm{~s}_{\mathrm{p}}=0.0250$ \\
1 & $10.0 \%, \mathrm{~s}_{\mathrm{p}}=0.0150$ & $13.5 \%, \mathrm{~s}_{\mathrm{p}}=0.0171$ \\
2 & $14.8 \%, \mathrm{~s}_{\mathrm{p}}=0.0177$ & $12.0 \%, \mathrm{~s}_{\mathrm{p}}=0.0162$ \\
$3-5$ & $18.0 \%, \mathrm{~s}_{\mathrm{p}}=0.0192$ & $16.5 \%, \mathrm{~s}_{\mathrm{p}}=0.0186$ \\
$>5$ & $10.2 \%, \mathrm{~s}_{\mathrm{p}}=0.0152$ & $7.0 \%, \mathrm{~s}_{\mathrm{p}}=0.0128$ \\
\hline
\end{tabular}

Table 6. Tree species depending on the planting location.

\begin{tabular}{ccc}
\hline Location in the Garden & More Evergreen Trees & More Deciduous Trees \\
\hline North side & $20.5 \%, \mathrm{~s}_{\mathrm{p}}=0.0202$ & $15.0 \%, \mathrm{~s}_{\mathrm{p}}=0.0179$ \\
East side & $13.5 \%, \mathrm{~s}_{\mathrm{p}}=0.0171$ & $14.5 \%, \mathrm{~s}_{\mathrm{p}}=0.0176$ \\
South side & $15.0 \%, \mathrm{~s}_{\mathrm{p}}=0.0179$ & $11.8 \%, \mathrm{~s}_{\mathrm{p}}=0.0161$ \\
West side & $5.2 \%, \mathrm{~s}_{\mathrm{p}}=0.0112$ & $8.8 \%, \mathrm{~s}_{\mathrm{p}}=0.0141$ \\
Did not answer & $45.8 \%, \mathrm{~s}_{\mathrm{p}}=0.0249$ & $50.0 \%, \mathrm{~s}_{\mathrm{p}}=0.0250$ \\
\hline
\end{tabular}

In order to make a forward to bioclimatic design, interior spaces do not suffice. Surroundings are also significant spaces that should be designed in line with bioclimatic principles. For the successful incorporation of green practices, it is crucial for citizens to adopt them in their residence. Basic guidelines include the proper landscape design, ideally with the introduction of low demanding native species [12], while the construction of green roofs could also be used for the balance of the microclimate in many cases [28].

\subsection{Adaptation to Environmentally Friendly and Energy Efficiency Practices}

The level of the citizens' adaptation to environmentally friendly and energy efficiency practices was examined and analyzed with the aim of descriptive statistics and the use of the statistical mean. In particular, citizens were asked to evaluate the capitalization of certain practices aiming to prevent energy losses in their houses including insolation preservation during winter; means and installations for the protection from strong winter winds; ways for the minimization of heating losses during winter; the protection from the summer sun; taking advantage of the summer breezes; and as regards to the removal of the heat which accumulates in summer in their residence. In Table 7, the results are interpreted, showing that the most important practices that have been adopted by the citizens of Orestiada are the minimization of the heating losses during winter, the protection from the summer sun and the protection from strong winter winds. It should be noted that the climate in the broader region is characterized by severe winters and hot summers.

Reliability analysis was performed to examine the consistency of the equivalent questions of the above multivariable. There is a significant ranking of the reliability coefficient alpha with a value of 0.808 . This is strong evidence for the research data in evaluating the same thing. Prior to the implementation of factor analysis, all the necessary checks were conducted. More specifically, the data appropriateness was checked; while it was also examined for the appropriateness of all the variables used in the model. The results of the factor analysis are shown in Table 8. The representations of the loads have shown that there is partial correlation in two factors for the six variables. There is a positive correlation between the variables' loads and the factor that is affecting the total degree fluctuation for 
this variable. The variables "belonging" to a specific factor are the ones with loads that overcome 0.5 value.

Table 7. The citizens' adaptation on environmentally friendly and energy efficiency practices in their residence.

\begin{tabular}{ccc}
\hline Variable & Statistical Mean & Standard Error \\
\hline Insolation preservation during winter & 5.77 & 2.576 \\
Protection from strong winter winds & 5.79 & 2.464 \\
Minimization of the heating losses during winter & 6.34 & 2.193 \\
Protection from the summer sun & 6.00 & 2.156 \\
Take advantage of the summer breezes & 5.29 & 2.210 \\
Removal of the heat which accumulates in summer & 5.11 & 2.121 \\
\hline
\end{tabular}

Table 8. Factor analysis loadings after rotation (numbers represented in bold indicate the factor that belongs to each variable).

\begin{tabular}{ccc}
\hline Variables & \multicolumn{2}{c}{ Factor Loadings } \\
& $\mathbf{1}$ & $\mathbf{2}$ \\
\hline Insolation preservation during winter & 0.384 & $\mathbf{0 . 6 7 3}$ \\
Protection from strong winter winds & $\mathbf{0 . 8 5 4}$ & 0.125 \\
Minimization of the heating losses during winter & $\mathbf{0 . 8 4 0}$ & 0.146 \\
Protection from the summer sun & $\mathbf{0 . 7 2 4}$ & 0.328 \\
Take advantage of the summer breezes & 0.075 & $\mathbf{0 . 9 0 5}$ \\
Removal of the heat which accumulates in summer & 0.198 & $\mathbf{0 . 8 2 0}$ \\
\hline
\end{tabular}

The burdens in bold represent the variables that belong to the specific factor.

The first factor termed as Energy efficiency practices of major acceptance consists of the variables "Protection from strong winter winds", "Minimization of the heating losses during winter" and "Protection from the summer sun". Accordingly, the second factor named as Energy efficiency practices of minor acceptance includes the variables "Insolation preservation during winter", "Take advantage of the summer breezes" and "Removal of the heat which accumulates in summer". The extraction of the two factors reveals that this grouping addresses the basic interventions which are closely affiliated with primary construction issues and are proven to be more acceptable by the citizens (listed in the first factor). On the other hand, the adaptation to some particular practices that prerequisite further investments, installation of a special equipment for the saving of energy or further construction works seem to have lower acceptance by the citizens.

\subsection{The Implementation of Hierarchical Log-Linear Analysis on the Citizens' Awareness on the Bioclimatic Housing Design}

In the next stage of data processing, the hierarchical log-linear analysis was conducted, in order to further examine the citizens' awareness on the bioclimatic housing design in line with the energy efficiency practices they adopt (Figure 3). Hence, with the application of two-step cluster analysis, the observations were listed into three clusters comprising the optimum solution.

Particularly, from the 385 citizens, $28.8 \%$ are listed in the first cluster, $33.2 \%$ in the second cluster and $37.9 \%$ in the third one. As regards to the variables' (continuous and categorical) relative significance towards the clusters' formation, the diagrammatic representations of Figure 3 indicate the tests with statistical significance. Variables are important in creating the cluster when the statistical value exceeds the critical value. In particular, for the continuous variables, it was observed that the variable "Energy efficiency practices of major acceptance" is in a close proximity with the critical value limit of the first cluster. Furthermore, the variable "Energy efficiency practices of minor acceptance" tends to hold an important role for the second cluster formation. Concerning the third cluster, both variables of "Energy efficiency practices of major acceptance" and "Energy efficiency practices of minor acceptance" are the 
reason for this formulation (Figure 3a,c,e). Whereas, concerning the categorical variables, the value of the statistical $X^{2}$ addressing both variables in the three clusters was higher compared with the limits of the critical value. This was explained by the fact that all the categorical variables in the analysis strongly affected the shaping of the three clusters (Figure $3 b, d, f)$.
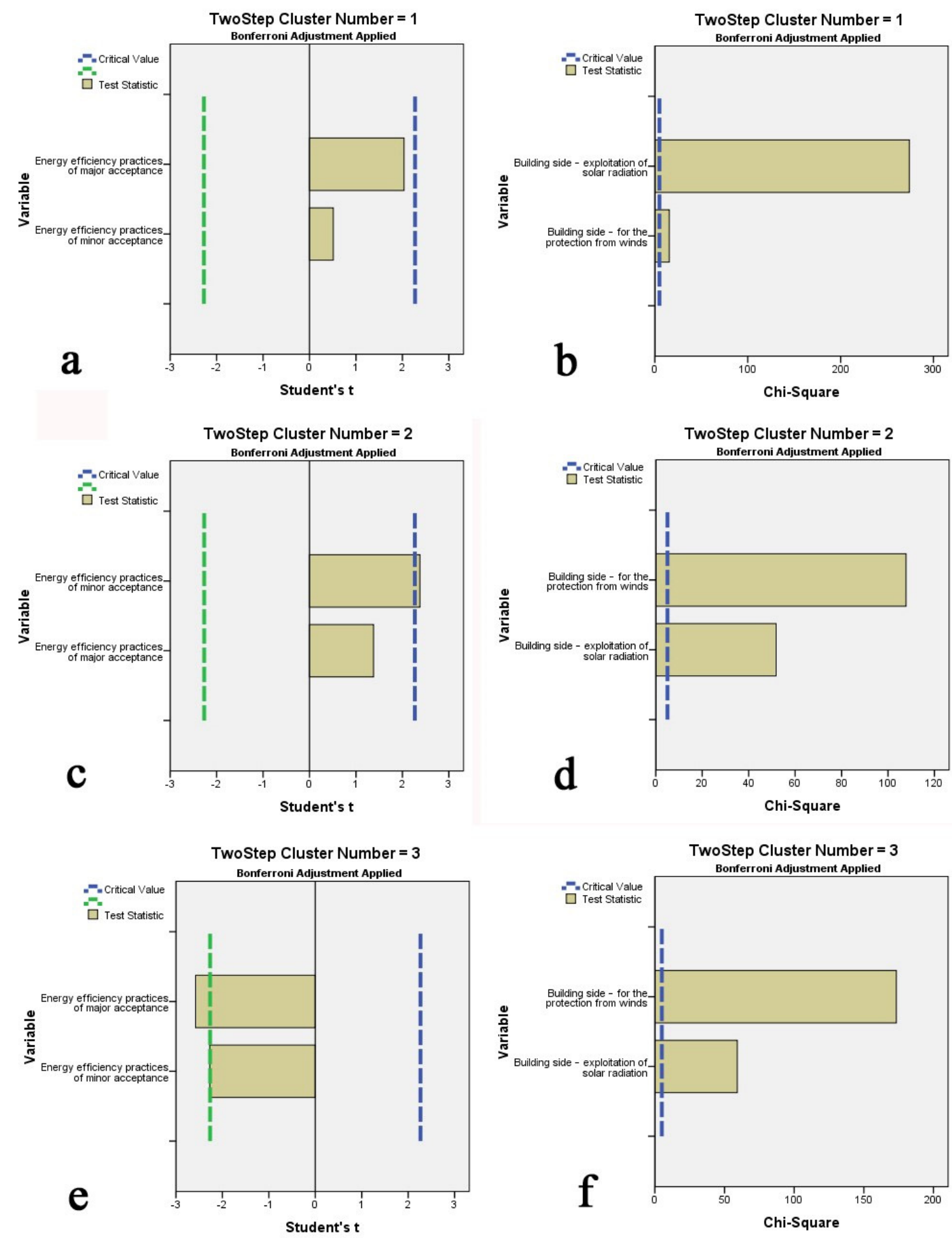

Figure 3. Diagrammatic representations of statistical tests of variables per cluster, with quantitative variables $(\mathbf{a}, \mathbf{c}, \mathbf{e})$, respectively categorical variables $(\mathbf{b}, \mathbf{d}, \mathbf{f})$. 
The characteristics of the three clusters are represented in Table 9. In particular, the practices adopted in the houses, with the highest acceptance by the citizens, have a positive value in the first and second cluster and a negative value in the third cluster. In addition, the practices adopted in houses with the lowest acceptance have a positive value in the second cluster, neutral to positive in the first cluster and negative in the third cluster. According to these findings, it seems that the citizens of the first and second cluster consider the adoption of environmentally friendly and energy efficiency practices under a more positive light. In addition, their positive concept is mainly estimated on practices engaging the efficient management of solar and wind energy.

Table 9. Interpretation of the cluster observations.

\begin{tabular}{|c|c|c|c|}
\hline Variables & Cluster 1 & Cluster 2 & Cluster 3 \\
\hline $\begin{array}{c}\text { Energy Efficiency Practices of } \\
\text { Major Acceptance }\end{array}$ & positive & positive & negative \\
\hline $\begin{array}{c}\text { Energy Efficiency Practices of } \\
\text { Minor Acceptance }\end{array}$ & neutral to positive & positive & negative \\
\hline $\begin{array}{l}\text { Building Side-Exploitation } \\
\text { of Solar Radiation }\end{array}$ & south & something else & something else \\
\hline $\begin{array}{l}\text { Building Side- } \\
\text { for the Protection } \\
\text { from Winds }\end{array}$ & north & north & something else \\
\hline \multicolumn{4}{|c|}{ With the use of Person $X^{2}$ check } \\
\hline $\begin{array}{l}\text { Need for Bioclimatic } \\
\text { Housing Design }\end{array}$ & disagree or totally agree & agree & $\begin{array}{l}\text { neither agree } \\
\text { nor disagree }\end{array}$ \\
\hline $\begin{array}{l}\text { Openings' Size (Windows } \\
\text { and Doors to the North) }\end{array}$ & narrow & average or narrow & do not exist or wide \\
\hline $\begin{array}{l}\text { Openings' Size (Windows } \\
\text { and Doors to the South) }\end{array}$ & wide or average & wide & do not exist or average \\
\hline $\begin{array}{l}\text { Interior Space Installations } \\
\text { on The North-South } \\
\text { Axis-Living Room }\end{array}$ & south & $\begin{array}{l}\text { in the middle of the } \\
\text { house or do not exist }\end{array}$ & $\begin{array}{l}\text { in the middle of the } \\
\text { house or do not exist }\end{array}$ \\
\hline $\begin{array}{c}\text { Interior Space Installations } \\
\text { on the North-South } \\
\text { Axis-Dining Room }\end{array}$ & south or north & $\begin{array}{l}\text { in the middle of } \\
\text { the house }\end{array}$ & $\begin{array}{l}\text { in the middle of the } \\
\text { house or do not exist }\end{array}$ \\
\hline Type of Residence & $\begin{array}{l}\text { detached house or on a } \\
\text { higher floor }\end{array}$ & $\begin{array}{l}\text { detached house or on the } \\
\text { first floor }\end{array}$ & first and second floor \\
\hline $\begin{array}{l}\text { House Orientation on the } \\
\text { North-South Axis }\end{array}$ & $\begin{array}{l}\text { north of the land upon } \\
\text { which the building } \\
\text { is situated }\end{array}$ & $\begin{array}{l}\text { south of the land upon } \\
\text { which the building } \\
\text { is situated }\end{array}$ & $\begin{array}{l}\text { in the middle of the land } \\
\text { upon which the building } \\
\text { is situated }\end{array}$ \\
\hline Educational Level & university & $\begin{array}{l}\text { technological ed. and } \\
\text { high school }\end{array}$ & lower level of education \\
\hline
\end{tabular}

The characteristics of each cluster of citizens are supplemented by the results of the analysis of the categorical variables. More specifically, it was observed that the citizens of the first cluster are aware and seem to comprehend that the side of the building that is important for the insolation is the south part. Moreover, they also acknowledge that the north part of the building is important for the protection of winds.

On the other side, as regards to the citizens of the second cluster, they only understood that the side of the building that should be given importance for the protection from the winds is the north part. Eventually, the citizens of the third cluster show the least knowledge on bioclimatic housing design patterns and disciplines.

Indeed, with the aid of Pearson's $X^{2}(\alpha<0.005)$ and in the lower part of Table 9 , it is provided the correlation among the three clusters with other variables about the citizens' characteristics.

The representations are the following: 
- The citizens of the first cluster disagree or totally agree with the need for bioclimatic housing design. They also claim that as regards to the construction and architecture of their houses, there are narrow windows and door openings to the north and wide or average to the south. Furthermore, as regards to the interior space installations that are most occupied, the living room is in the south and the dining room is located in the south or north part of the house. Finally, the citizens of this cluster own a detached house or an apartment on a higher floor of a building. Their residence is in the north part of the land upon which the building is situated. The correlation with the education level shows that these citizens are of an advanced educational status as they mainly hold a university degree.

- Citizens that belong to the second cluster merely agree with the need for integrating bioclimatic housing design. The same also state that they reside in a house with average or narrow openings of windows and doors to the north and that these openings are wide to the south axis. Added to that, they declare that their living room is situated in the middle of the house. The citizens of the second cluster are owners of a detached house or an apartment on the first floor and their house is built on the south part of the land upon which the building is situated. Finally, their education level is intermediate in comparison with the citizens of the first and the third cluster.

- The third cluster citizens neither agree nor disagree with the need for establishing bioclimatic housing design. Concerning the existing status of their residence in terms of basic bioclimatic housing design, they describe the window and door openings as being wide to the north or not existing at all. As regards to the south axis, they claim to have average window and door openings or none at all. Moreover, interior space installations in their residence involve a living room in the middle of the house or these do not exist. As for the dining room, they indicate the same positioning. Concerning the type of residence, they have an apartment on the first or second floor, in the middle of the land upon which the building is situated. In this cluster, citizens are of a lower educational level.

\section{Discussion}

It is evident that the existing situation of the building stock in the Municipality of Orestiada is a challenging issue as part of an effort to harmonize elements of bioclimatic housing design and their adaptation in the existing of future buildings. In fact, the embracing of this point of view coincides with the fact that only $1.5 \%$ of the buildings in Orestiada were constructed after 2010 and accordingly meet the minimum energy performance requirements of the Hellenic Regulation on the Energy Assessment of Buildings-KENAK. Additionally, it should be taken into consideration that the majority of the citizens are not aware of the need and benefits arising with the establishment of bioclimatic systems; although, according to Manzano-Agugliaro et al. [29], such systems will serve as a reduction of energy consumption along with the enhancement of the climate comfort level in their houses.

In fact, the hierarchical log-linear analysis revealed that despite the fact that the citizens of the first and second cluster hold a positive view on the adoption of environmentally friendly and energy efficiency practices, this mainly addresses energy efficiency on solar and wind systems that are established with the basic architecture principles. These interventions mostly took place during the construction phase of their residence, such as the determination of the side of the building that can take advantage of the insolation or, respectively, provide protection from winter winds. However, the majority of citizens that belong in the third cluster seem to hold poor knowledge on bioclimatic housing design patterns and disciplines.

Moreover, it is of outmost importance for the citizens to understand and adopt new green practices and efficiently use energy in their residence [15]. The basic principles of this effort are related with sustainability goals, namely the sustainable exploitation of the natural environment and its resources. Thus, the citizens' adaptation to primary and, in turn, to advanced bioclimatic patterns aims to preserve energy and establish a holistic approach towards environmentally friendly attitudes at both passive and active levels of construction solutions. 
Furthermore, bioclimatic housing design implies the construction of houses designed in a way that will meet the citizens' energy needs, through the optimal utilization of the building comfortably and the existing local and microclimatic environment [30]. The adaptation to a bioclimatic residence presupposes that the main openings and the main face of the house should be oriented to the south, while, in the north, there should be small openings and solid walls. Additionally, the openings should be designed in a way to provide transparent ventilation [31,32]. Nonetheless, most of the citizens of Orestiada seem not to be aware of energy and/or bioclimatic contemporary architecture interventions. In fact, only the citizens of the first cluster are the advocates of adapting bioclimatic housing design. The adaptation of specific patterns and systems plays a crucial role in achieving improved interior environments by the conservation of energy and the incorporation of practices that have proven to be more efficient in the building construction sector; such as the passive thermal systems for the improvement of thermal comfort in heating and cooling of interior spaces [12]. In order to achieve efficient energy management on a city level, it is of great importance to make a forward in utilization of green energies. Self-efficiency in energy production on site could be an innovative solution the housing sector; namely by the use of renewable energy [33] such as solar or wind energy.

The citizens of the third cluster, who are apparently the most reluctant in adapting bioclimatic housing design, argue that their windows and door openings are wide and oriented to the north or that they do not exist. Moreover, as regards to the south axis, they claim to have average window and door openings or none at all. However, there is a different view concerning the citizens of the first cluster; they stated to have, at least, narrow windows and door openings to the north in their houses and wide or average ones to the south. The citizens of this cluster have proven to adapt more efficiently to passive solar strategies that are based on cooling or heating strategies, which passively absorb or protect from solar radiation and are using slightly or not at all mechanical devices [34]. According to Bughio et al. [10], cross-ventilation via the proper placement of openings, could improve external shading devices, and create more comfortable indoor environmental quality.

As regards to the positioning of the most used rooms of the house, namely the living room and the dining room, only the citizens of the first cluster have stated to have the living room in the south part of the house. The citizens of the second and third cluster claim to have placed the living room in the middle of the house, while, for some citizens of the third cluster, the living room does not exist at all. Similar responses were recorded for the dining room positioning. From the first phase of designing a building, designers should consider the internal existing conditions required to control variation of room temperature and humidity, and the positioning of specific rooms such as the kitchen, laundry and bathroom. The design and recommendation for the position of the rooms should be in combination with the external climatic local conditions [35]. Indeed, the room design should fulfill the standards for optimum thermal comfort with low energy consumption and sustain a good indoor air quality [36]. Concerning the positioning of the living room, this should provide good indoor conditions during daytime, when it is mainly used [37].

Concerning the orientation of the house in the plot and the ownership status of the house, the citizens of the first cluster that belong to the highest educational level seem to be the most privileged and in accordance with basic bioclimatic housing design principles. This arises by the fact that they own a detached house or an apartment on a higher floor of a building, which is situated in the north part of the land upon which the building is situated. In line with Akadiri et al. [12], the orientation of the building is part of bioclimatic design that aims to passive energy utilization. Thus, it should be taken into consideration and conceptualized in a macro and microclimate framework from the beginning of the design procedure by the architects. In a similar study that was conducted in Finland, a country with a different climatic condition, it seems that there is a strong association between the citizens' income and amount of energy they consume to fulfill their needs. The same study also revealed that carbon emissions are similar for detached houses in suburban regions and for dense building blocks in rural areas [38]. 
A gradual relegation of the ownership conditions and bioclimatic benefits is observed respectively in the second and third cluster. Particularly, the citizens of the second cluster are of an intermediate educational level, owners of a detached house or an apartment on the first floor, and their house is situated at the south of the property land. The citizens of the third cluster have the lowest educational level and they reside in an apartment on the lowest floors, that is situated in the middle of the land upon which the building is situated. It was proven that the proper orientation of the building contributes to natural ventilation, to lighting and to the reduction of energy consumption and emissions by devices for artificial light and air-conditioning systems [39]. In addition, other findings from areas with similar climate conditions and Mediterranean climate, such as Italy, have shown that except for orientation, openings, exposure to weather conditions and employment of the local natural resources, that the building shape plays a critical role in the thermal behavior of buildings [40].

\section{Conclusions}

The majority of the respondents are aware of the term 'bioclimatic housing design' yet, their knowledge on passive solar systems is limited. The citizens of Orestiada recognize the importance of the northern house orientation that is foreseen in order to ensure protection from winds as well as heat retention. However, some of the basic principles of bioclimatic design, such as the southern location of the building, seems not to have a significant adaptation in the housing of Orestiada.

On the other hand, the majority of the citizens believe that the basic principles of bioclimatic design are applied in their houses. Indeed, for an important amount of the citizens, it seems that there is a partial application of bioclimatic housing design. Notwithstanding, for the minority of the citizens, there is no adaptation, even as regards to the basic principles of bioclimatic design.

In line with the findings highlighted by the application of hierarchical log-linear analysis, it could be underscored that the citizens of the first cluster seem to adapt at least to the basic principles of bioclimatic housing design; while for the ones that belong to the second cluster, there is a mere adaption to the primary principles. Nonetheless, in the last group of citizens, none of the basic principles of bioclimatic design seems to be adopted.

Reasonably, there is a gap of awareness on innovative energy saving systems. It is evident that there was low acceptance by the citizens on the need to install advanced systems of energy saving purposes such as active solar energy systems. Possibly, this was regarded as a questioning issue as these systems demand further investments and direct costs that are included at the first stage of their installation. In Greece, there is an ongoing financial program for the transformation of the building sector into the sustainable sector. The program "Saving at home" was introduced in 2007 and it is supported by the European Regional Development Fund and national funds. Unfortunately, there is still low absorption of structural funds. An answer for this situation could be the low dissemination of the program and its potential. Another important issue is that citizens regard it as questionable. In fact, there is a lot of mistrust due to the fact that most of the candidates for implementing the program and improving their residence in line with KENAK standards, have applied in the past and had no feedback for years. Added to that, a lot of bureaucratic and demanding procedures constitute another reason for the citizens' abstention.

Another point to consider is the microclimate of the area. Particularly, the significant humid climate of Orestiada, the moderate sunshine and the restricted but intensely hot summer period, comprise some of the key factors for which bioclimatic housing design should be adapted in the major part of the buildings in the broader area. This means that there is an indisputable need for the designing of buildings with the engagement of proper and rational principles in terms of location and orientation of the building; size - orientation and allocation of the door and window openings; the protection of the building shell (thermal insulation, wind protection and solar radiation protection)-which is the most important feature that designers of housing in Greece, such as engineers and architects, should take into account. It is also essential for the homeowners to be aware of the bioclimatic framework 
and set performance indicators as a prerequisite for a contract assignment to a housing designer or to a technician.

Taking everything into consideration, it would be argued that sustainable and bioclimatic buildings do not suffice to protect the natural environment. Raising awareness and creating consciousness in environmental, sustainability and energy efficiency issues stands as a necessary condition for the citizens to be able to recognize the value of embracing bioclimatic housing design practices. The citizens Orestiada are quite aware and environmentally conscious. Therefore, with the aim of raising awareness programs, they will have access to higher levels of information, which, in turn, will serve as a means of adaptation to bioclimatic practices.

Nevertheless, the measures taken within a policy framework of sustainable development ought not to be considered as fragmented and isolated. In fact, efficient city management should regard cities as integrated units. Nowadays, an incorporated strategy is the first and foremost demand in order to address the intense problems of the natural and urban environment under a holistic point of view. If we are willing to establish strategic planning for the integrated management of smart cities, aiming both at sustainability and the improvement of citizens' quality of life, this implies the effective participation, cooperation and interaction of key stakeholders in decision making. In conclusion, it appears that the props of this procedure are the public services for construction and technical schemes, as well as the enforcement of certain policies, measures and regulations in the field of transport, renovation, energy, economic development, social cohesion and other parameters that set up the picture of a city.

Finally, due to research limitations, it was not possible to investigate some specific characteristics of the housing sector in the Municipality of Orestiada in order to attribute a more elaborative view of the existing establishments. To this end, it is highly recommended, for future research, a deeper examination of specific features that comprise the city housing typology such as building heights, floor numbers, structural materials, orientation and household size. Additionally, a better analysis is suggested for the outdoor spaces such as access to gardens and watering mechanisms used. Other points that need to be investigated in the future is if renewable energy systems can be established and used to cover the household energy needs, the introduction of innovation and smart systems for energy efficiency and also the citizens' performance in taking up funding programs such as the periodical European structural and investment funds, for the transition to an energy efficient community.

Supplementary Materials: The questionnaire is available online at http://www.mdpi.com/2071-1050/12/12/4984/s1.

Author Contributions: Conceptualization, V.A.; Formal analysis, S.T. and M.G.; Methodology, S.T. and M.G.; Project administration, P.K.; Resources, V.A. and P.K.; Supervision, S.T.; Writing-original draft, V.A.; Writing-review \& editing, V.A. and P.K. All authors have read and agreed to the published version of the manuscript.

Funding: This research received no external funding.

Conflicts of Interest: The authors declare no conflict of interest.

\section{References}

1. United Nations, Department of Economic and Social Affairs. 68\% of the World Population Projected to Live in Urban Areas by 2050, Says UN. Available online: https://www.un.org/development/desa/en/news/ population/2018-revision-of-world-urbanization-prospects.html (accessed on 24 April 2020).

2. Romero-Lankao, P.; Gnatz, D.M.; Wilhelmi, O.; Hayden, M. Urban Sustainability and Resilience: From Theory to Practice. Sustainability 2016, 8, 1224. [CrossRef]

3. Ahmed, Z.; Zafar, M.W.; Ali, S. Danish, Linking urbanization, human capital, and the ecological footprint in G7 countries: An empirical analysis. Sustain. Cities Soc. 2020, 55, 102064. [CrossRef]

4. Bajcinovci, B.; Jerliu, F. Achieving Energy Efficiency in Accordance with Bioclimatic Architecture Principles. Environ. Clim. Technol. 2016, 18, 54-63. [CrossRef]

5. Ji, Z.; Xu, Y.; Wei, H. Identifying Dynamic Changes in Ecosystem Services Supply and Demand for Urban Sustainability: Insights from a Rapidly Urbanizing City in Central China. Sustainability 2020, $12,3428$. [CrossRef] 
6. Zoraghein, H.; O’Neill, B.C. U.S. State-level Projections of the Spatial Distribution of Population Consistent with Shared Socioeconomic Pathways. Sustainability 2020, 12, 3374. [CrossRef]

7. European Commission. Energy Performance of Buildings Directive. Available online: https:/ec.europa.eu/ energy/topics/energy-efficiency/energy-efficient-buildings/energy-performance-buildings-directive_en (accessed on 23 April 2020).

8. Calzada, I. (Smart) Citizens from Data Providers to Decision-Makers? The Case Study of Barcelona. Sustainability 2018, 10, 3252. [CrossRef]

9. Tovar Alcázar, M.R.; García Chávez, J.R. Educational Program for Promoting the Application of Bioclimatic and Sustainable Architecture in Elementary Schools. Energy Procedia 2014, 57, 999-1004. [CrossRef]

10. Bughio, M.; Schuetze, T.; Mahar, W.A. Comparative Analysis of Indoor Environmental Quality of Architectural Campus Buildings' Lecture Halls and its' Perception by Building Users, in Karachi, Pakistan. Sustainability 2020, 12, 2995. [CrossRef]

11. Oliveira, S.; Marco, E. Role of 'Community Spaces' in Residents' Adaptation to Energy-Efficient Heating Technologies-Insights from a UK Low-Energy Housing Development. Sustainability 2018, 10, 934. [CrossRef]

12. Akadiri, P.O.; Chinyio, E.A.; Olomolaiye, P.O. Design of A Sustainable Building: A Conceptual Framework for Implementing Sustainability in the Building Sector. Buildings 2012, 2, 126-152. [CrossRef]

13. KENAK-Greek Regulation for the Energy Efficiency of Buildings. Available online: https://www.buildup. eu/en/practices/publications/kenak-greek-regulation-energy-efficiency-buildings (accessed on 25 April 2020).

14. Matis, K. Forest Sampling; Democritus University of Thrace: Xanthi, Greece, 2001.

15. Hoyos, D. The state of the art of environmental valuation with discrete choice experiments. Ecol. Econ. 2010, 69, 1595-1603. [CrossRef]

16. Pagano, M.; Gauvreau, K. Elements of Biostatistics; Ellin Publications: Athens, Greece, 2000.

17. Siardos, G.K. Multivariate Statistical Analysis Methods. In Part I: Exploring the Relations between Variables; Zitis Publications: Thessaloniki, Greece, 1999.

18. Frangos, C.K. Methodology of Market Research and Data Analysis with the Use of the Statistical Package SPSS for Windows; Interbooks Publications: Athens, Greece, 2004.

19. Howitt, D.; Gramer, D. Statistics with the SPSS 11 for Windows; Kleidarithmos Publications: Athens, Greece, 2003.

20. Djoufras, I.; Karlis, D. Elements of Multivariate Data Analysis; University of the Aegean: Chios, Greece, 1997.

21. Harman, H.H. Modern Factor Analysis; The University of Chicago Press: Chicago, IL, USA, 1976.

22. Tabachick, B.G.; Fidell, L.S. Using Multivariate Statistics, 2nd ed.; Harper and Row: New York, NY, USA, 1989.

23. Antonopoulou, S. Bioclimatic Architecture and Sustainable Development-Methods and Examples in Specific Buildings. Bachelor's Thesis, School of Environment, Geography and Applied Economics, Department of Home Economics and Ecology, Harokopio University, Athens, Greece, 2009.

24. Kaniadaki, M. Energy Efficiency Housing. Energy Efficiency Methods and Systems in Modern Greek Housing. Bachelor's Thesis, Department of Mechanical Engineering, Technological Educational Institute of Crete, Heraklion, Greece, 2011.

25. Zoumbourlis, G.; Etmektzoglou, S. Bioclimatic Design in the Building Construction Sector. Bachelor's Thesis, Department of Civil Engineering, Technological Educational Institute of Piraeus, Aigaleo, Greece, 2014.

26. Hegazi, K. Bioclimatic Construction and Sustainable Development. Bachelor's Thesis, School of Mechanical Engineering, National Technical University of Athens, Athens, Greece, 2009.

27. Rizou, S. Bioclimatic and Energy Efficiency Building Management. The Case of a Multi-Use Space of Shopping Mall and Restaurants in Volos Greece. Master's Thesis, Interdepartmental Master Programme Law and Energy Engineering, Aristotle University of Thessaloniki Faculty of Law, School of Law, Thessaloniki, Greece, 2017.

28. Salkini, H.; Greco, L.; Lucente, R. Towards Adaptive Residential Buildings Traditional and Contemporary Scenarios in Bioclimatic Design (the Case of Aleppo). Procedia Eng. 2017, 180, 1083-1092. [CrossRef]

29. Manzano-Agugliaro, F.; Montoya, F.G.; Sabio-Ortega, A.; García-Cruz, A. Review of bioclimatic architecture strategies for achieving thermal comfort. Renew. Sustain. Energy Rev. 2015, 49, 736-755. [CrossRef]

30. Mohammed, U.A.; Alibaba, H.Z. Application of Bioclimatic Design Strategies to Solve Thermal Discomfort in Maiduguri Residences, Borno State Nigeria. Imp. J. Interdiscip. Res. (IJIR) Peer Rev. Int. J. 2018, 4, 227-233.

31. Center for Renewable Energy Sources. Bioclimatic Design and Passive Solar Systems. Available online: http://www.cres.gr/kape/energeia_politis/energeia_politis_bioclimatic_eng.htm (accessed on 20 April 2020). 
32. Bodach, S.; Lang, W.; Hamhaber, J. Climate responsive building design strategies of vernacular architecture in Nepal. Energy Build. 2014, 81, 227-242. [CrossRef]

33. Heinonen, J.; Kyrö, R.; Junnila, S. Dense downtown living more carbon intense due to higher consumption: A case study of Helsinki. Res. Lett. 2011, 6, 034034. [CrossRef]

34. Duraković, B. Passive Solar Heating/Cooling Strategies. In PCM-Based Building Envelope Systems. Green Energy and Technology; Springer: Cham, Switzerland, 2020; pp. 39-40. [CrossRef]

35. Sada, G.K.A.; Salih, T.W.M. Enhancing Indoor Air Quality for Residential Building in Iraq as a Typical Case of Hot Arid Regions. In Proceedings of the Workshop on Indoor Air Quality in Hot Arid Climate, Kuwait City, Kuwait, 3-4 April 2017; Yassin, M.F., Ed.; Kuwait Institute for Scientific Research: Kuwait City, Kuwait, 2017; pp. 113-121.

36. Pamonpol, K.; Areerob, T.; Prueksakorn, K. Indoor Air Quality Improvement by Simple Ventilated Practice and Sansevieria Trifasciata. Atmosphere 2020, 11, 271. [CrossRef]

37. Abdallah, A.S.H. New passive cooling as a technique for occupant comfort and indoor air quality in hot arid climate, Egypt. In Proceedings of the Workshop on Indoor Air Quality in Hot Arid Climate, Kuwait City, Kuwait, 3-4 April 2017; Yassin, M.F., Ed.; Kuwait Institute for Scientific Research: Kuwait City, Kuwait, 2017; pp. 162-168.

38. Heinonen, J.; Junnila, S. Implications of urban structure on carbon consumption in metropolitan areas. Res. Lett. 2011, 6, 014018. [CrossRef]

39. Chel, A.; Kaushik, G. Renewable energy technologies for sustainable development of energy efficient building. Alex. Eng. J. 2018, 57, 655-669. [CrossRef]

40. Albatici, R.; Passerini, F. Bioclimatic design of buildings considering heating requirements in Italian climatic conditions. A simplified approach. Build. Environ. 2011, 46, 1624-1631. [CrossRef]

(C) 2020 by the authors. Licensee MDPI, Basel, Switzerland. This article is an open access article distributed under the terms and conditions of the Creative Commons Attribution (CC BY) license (http://creativecommons.org/licenses/by/4.0/). 